\title{
Transformações institucionais: um estudo sobre os novos arranjos familiares
}

\section{Institutional transformations: a study about the new family arrangements}

\author{
Marina Rocha Zani1, Sonia Regina Vargas Mansano²
}

Resumo

\begin{abstract}
As instituições sociais são tão antigas que sua origem nem sequer pode ser facilmente demarcada. Elas são formadoras de normas e valores que organizam a convivência social e participam da produção de modos de vida historicamente compartilhados. Tais normas podem ser transmitidas na forma de leis ou pela convivência cotidiana. A família é uma das mais antigas instituições sociais e também uma das que mais sofre modificações na atualidade. Esta pesquisa teórica tem por objetivo analisar a instituição familiar a partir de uma perspectiva histórica, buscando compreender os efeitos sociais dos arranjos familiares que ganharam mais visibilidade recentemente, bem como os afetos experimentados diante dessas novas composições. Como resultado parcial, pode-se perceber que apesar de os arranjos familiares emergentes serem variados e disseminados no social, eles ainda encontram resistência em relação ao padrão hegemônico burguês que configura o imaginário social. A conclusão parcial deste estudo mostra que as famílias atuais encontram-se diante do desafio político de inventar e sustentar outras maneiras de conviver tanto entre seus membros quanto em relação à sociedade, ainda bastante referida ao modelo nuclear tradicional.
\end{abstract}

Palavras-chave: Família; Instituições; Afetos

\begin{abstract}
Social institutions are so ancient that its origin even can be easily outlined. They are forming of norms and values that organize the social coexistence and participate in the production of historically shared ways of living. Such standards may be transmitted in the form of laws or for everyday living. The family is one of the oldest social institutions and also the one who suffers most modifications today. On the emergence of new family arrangements, this theoretical research aims to analyze the family institution from a historical perspective, seeking to understand the social effects the family arrangements that have more visibility recently, as well as the emotions experienced in these new compositions. As a partial result, one can realize that even though the family arrangements are varied and widespread in the social, they still find resistance compared to standard mainstream bourgeois that configures the social imaginary. The partial completion of this study shows that the current families are facing the political challenge of making and sustaining other ways to live among its members and in relation to society, still referred to the traditional nuclear model.
\end{abstract}

Keywords: Family; Institutions; Affections

\footnotetext{
1 Psicóloga formada pela Universidade Estadual de Londrina.

${ }^{2}$ Doutora em Psicologia Clínica pela PUC/SP. Docente do Programa de Pós-Graduação em Psicologia, do Programa de PósGraduação em Administração e do Departamento de Psicologia Social e Institucional da Universidade Estadual de Londrina. E-mail: mansano@uel.br
} 


\section{Introdução}

Um enunciado bastante comum difundido em nosso tempo histórico é de que instituição familiar encontra-se em crise. Geralmente investida de uma conotação negativa, a ideia de crise remete à perda de controle sobre algo que até então estava supostamente delimitado em uma forma conhecida e compartilhada. Na língua portuguesa, a palavra crise possui diversos sentidos. No trabalho de Houaiss (2009, p. 573), por exemplo, duas de suas acepções chamam atenção: primeiro, ele fala de um "estado de incerteza, vacilação ou declínio"; em seguida, descreve a noção de crise como "episódio desgastante, complicado; situação de tensão, disputa, conflito".

O fato de a família ser percebida em nossos dias como uma instituição em crise evoca o estado de incerteza e tensão descrito por Houaiss (2009) e, com isso, aciona os mais diferentes agentes sociais e áreas de conhecimento na busca pela compreensão sobre o que está lhe acontecendo. Em nosso entendimento, entretanto, a chamada crise da família, longe de se configurar como um problema, atesta que as instituições sociais são invenções móveis e transitórias que têm na transformação sua condição de existência. Sem tal variação, a queda na passividade e na estagnação levaria à sua extinção. Isso é tão real que algumas instituições, mais lentas no processo de transformação, correm o risco de sofrer uma espécie de falência social, cujo efeito em longo prazo é o esquecimento e o abandono de seus pressupostos. Nesse sentido, a crise funciona como uma espécie fonte vital de onde é possível retirar energia para reaver valores e normas, bem como experimentar novas percepções e sensibilidades. Tais crises cooperam, assim, para desenhar novos contornos institucionais.

É a partir dessa perspectiva mutante que tomaremos em análise a instituição família. Mas, afinal, o que é uma instituição? Quais suas funções sociais? Como ela se organiza para acompanhar as transformações históricas que são ensaiadas no campo social? Atento a essas questões, o presente estudo justifica-se ao evidenciar que a instituição família atrai a atenção não apenas da academia e do cidadão comum, como também das instâncias governamentais que, como veremos adiante, estão ocupadas em definir os pressupostos para essa complexa instituição, recorrendo à discussão legal sobre sua organização. Com isso, as novas configurações familiares, que ganharam mais visibilidade no contemporâneo, enfrentam o desafio de alcançar a legitimação social que perpassa questões de ordem econômica, relacional, política e jurídica. Para tanto, delineamos como objetivo do estudo compreender as instituições sociais, em especial a familiar, em uma perspectiva histórica, atentando para suas crises e para os novos afetos que elas colocam em circulação.

\section{Algumas Considerações Quanto ao Percurso Metodológico}

Este trabalho foi fundamentado em pesquisa teórica sobre a noção de instituições, dando ênfase à instituição familiar. Para tanto, foi realizada uma problematização acerca dos valores e modos de viver compartilhados pela população em diferentes épocas. A família, como uma das primeiras instituições sociais em que o indivíduo geralmente é inserido quando nasce, chama a atenção de diferentes áreas de conhecimento por seus processos de mutação mais acelerados na atualidade, os quais vêm ganhando contornos distintos desde a segunda metade do século XX. Assim, para o contexto desta pesquisa, a definição de instituição foi compreendida com base em autores como Baremblitt (2002), Foucault (1987) e Lourau (1995).

A investigação segue o seguinte trajeto: Primeiramente, foi realizada uma breve caracterização histórica que buscou demarcar as principais mudanças ocorridas nas instituições familiares. Para isso, foi utilizado como referência 
os estudos de Reis (1994), Ariès (1981) e Foucault (2001), que apresentam as mutações dessa instituição desde o século XVI, começando pela descrição das famílias aristocráticas e camponesas, passando pelas famílias proletária e burguesa dos séculos XVII e XIX, até chegar ao século XX. Neste último, houve a cristalização e expansão dos costumes da família nuclear burguesa, sendo que esta é tomada como referência até os dias de hoje.

Em seguida, foram analisadas as mudanças mais recentes nas constituições familiares, tendo como base os dados estatísticos disponibilizados pelo Instituto Brasileiro de Geografia e Estatística(IBGE), referente ao censo populacional do ano de 2010 (IBGE, 2012), que evidenciou uma multiplicação nas maneiras de organizar essa instituição. Nesse momento, dirigimos a atenção para o final do século XX e início do XXI, valendo-nos de autores como Féres-Carneiro (1998), Hintz (2001), Singly (2007) e Zauli (2011), que caracterizaram e descreveram os novos arranjos da família contemporânea. Nessa seção, serão apresentados três arranjos familiares: as famílias reconstituídas, as famílias sem filhos e as famílias homoafetivas. O critério para essa seleção foi a incidência com que tais arranjos aparecem nos dados do censo de 2010, tomado aqui como referência.

Por fim, a partir dos estudos histórico e teórico apresentados, foi analisado como a sociedade atual acolhe e sustenta os modos de vida que, em alguma medida, rompem com a configuração institucional da família nuclear burguesa, utilizando, para isso, a noção de sustentabilidade afetiva. Esta última envolve o grau de abertura e disponibilidade para acolher, experimentar e sustentar afetos que emergem na contemporaneidade à medida que se efetuam as mutações institucionais (MANSANO, 2016). Essa análise, que aparece nas considerações finais, serviu para problematizar os novos sentidos que estão sendo produzidos nessas configurações familiares emergentes.

\section{As Funções Sociais das Instituições e suas Mutações}

As instituições sociais estão presentes em diversas culturas, sendo tão antigas e multifacetadas que sua origem nem sequer pode ser facilmente demarcada. A definição de instituição, tal qual compreendida por Baremblitt (1994, p. 27), envolve uma "forma organizada de associação humana" que se diferencia pelo "grau de formalização que adotem". Dessa maneira elas "podem ser leis, podem ser normas e, quando não são enunciadas de maneira manifesta, podem ser pautas, regularidades de comportamento" (BAREMBLITT, 1994, p. 27). Assim, as instituições apresentam-se como normatizadoras de atitudes e relações, servindo como referência que dá direção às relações sociais, organizando-as de acordo com os valores vigentes em cada época. É possível dizer também que elas se constituem em formas visíveis dotadas de organização, que pode ser política ou material, as quais produzem modelos de ação e integram seus elementos numa ordem social, podendo ou não estipular sanções e castigos em relação a possíveis transgressões (BAREMBLITT, 2002; LOURAU, 1995).

Envolvendo um conjunto amplo de valores, construídos e legitimados no social, é possível conceber cada instituição social como um universo diferente dos demais pelo fato de cada uma ter suas permissões, repressões e regras de convivência específicas, sendo estas amplamente cristalizadas e compartilhadas coletivamente. Desse modo, o indivíduo tende a pensar e agir segundo o que é estabelecido pelas instituições. À medida que ocorre tal adesão e compartilhamento de valores, podese dizer que ele faz parte das mesmas (RAMOS; NASCIMENTO, 2008). Todavia, outro ponto a ser compreendido sobre as instituições é que, apesar de sua caracterização própria e independente, elas se articulam, formando uma rede institucional que conecta pessoas, afetos e desejos. 
Desde o século XVIII, caracterizado por Foucault (1987) como um tempo histórico marcado pela disciplina, o humano foi inscrito em uma rede de instituições caracteristicamente disciplinares que se entrelaçaram e, ao mesmo tempo, guardaram diferenças umas em relação às outras. Para garantir a disseminação e internalização da disciplina por cada indivíduo, tais instituições agiram de forma rigorosa e sistemática sobre os corpos. Diz Baremblitt (2002, p. 27): "Em um plano formal, uma sociedade não é mais que isso: um tecido de instituições que se interpenetram e se articulam entre si para regular a produção e a reprodução da vida humana sobre a terra e a relação entre os homens". Nota-se, nessa consideração do autor, o que talvez não seja tão fácil de perceber: o fato de que somos inseridos e afetados por várias instituições diferentes durante a nossa trajetória de vida, as quais funcionam de maneira integrada. Nesse sentido, pode-se dizer que uma instituição necessita da outra para promover o governo da coletividade, sendo que o seu conjunto é o que regula a vida em sociedade. Lourau (1995) afirma que a regulamentação da atividade e da vida é equivalente a um corte entre o que é possível fazer dentro de uma organização específica e o que não é; entre o que é desejável ou não para manter a coesão do conjunto.

É importante acentuar que as instituições sociais são puramente artificiais, no sentido de serem criadas pelo homem para promover uma melhor convivência social, tendo como um de seus focos a adesão aos valores socialmente compartilhados e a produtividade de seus agentes. Em certa medida, segundo Baremblitt (2002), as instituições ganharam forma e consistência em virtude de necessidades básicas e gerais dos grupos sociais e começaram a ficar mais complexas à medida que as sociedades cresceram. Porém, a concepção de instituição como supridora das necessidades físicas e sociais do homem tem seus limites, uma vez que, em todas elas, o delineamento da noção de necessidade é produzido e transformado historicamente.
Esta produção pode abrir espaço para a naturalização de alguns valores, disseminando a falsa impressão de que eles existissem de maneira perene. O perigo dessa naturalização é promover a mera reprodução da vida em sociedade. Ao naturalizarmos valores e instituições, considerandoos absolutos e eternos, tendemos ao distanciamento dos debates, críticas e problematizações sobre a convivência social e suas mutações.

Decorrente dessa naturalização, certas instituições como, por exemplo, a familiar, transmite a impressão equivocada de manter uma permanência e rigidez nos seus valores. Esse equívoco, entretanto, é logo contrariado se observamos que o cotidiano e as relações sociais de seus membros estão em constante mutação. São perceptíveis, principalmente na contemporaneidade, as transformações sofridas pelas instituições disciplinares, como bem ressaltou Deleuze quando relatou a emergência de uma crise institucional, que ocorreu "em favor de novas forças que se instalavam lentamente e que se precipitariam depois da Segunda Guerra Mundial: sociedades disciplinares é o que já não éramos mais, o que deixávamos de ser" (DELEUZE, 1992, p. 219). Isso aconteceu à medida que a sociedade experimentou novos conflitos, impasse e rupturas em seus desejos e necessidades.

Dessa forma, ainda que as instituições sociais caracterizem-se pela estabilidade e manutenção de sua estrutura no decorrer do tempo, Baremblitt (2002) afirma que existe uma força de resistência a esse processo de estagnação. Nesse sentido, é importante perceber que as mutações sociais não cessam, uma vez que as instituições são vivas e atentas ao que ocorre na sociedade: novas maneiras de agir e de conviver vão surgindo e impedem que a vida em sociedade fique estagnada. Assim, as instituições enfrentam uma relação complexa entre o que é chamado por Baremblitt (1994, p. 31) de "instituinte", que engloba as forças incontroláveis que tendem a transformar os valores; e o "instituído", que nada mais é do que o efeito mais duradouro das 
atividades revolucionárias e mutantes do instituinte. Segundo o autor, instituinte e instituído formam uma dupla permanentemente fluida e elástica. É interessante notar que o instituinte é um processo constante, que tende a produzir mudanças nas instituições. Enquanto o instituído é um processo estático que garante a reprodução e manutenção temporária das mesmas. Tanto o plano estável do instituído quanto os movimentos gerados pelas práticas instituintes são de extrema importância para compreensão da vida social e suas mutações.

Os valores internalizados e assumidos pelos indivíduos que compõem uma instituição são acumulados durante umlongo período, contando com a memória e a prática de um coletivo institucional. Sendo assim, é impossível demarcar a origem de uma instituição, tendo em vista que diferentes rupturas e mudanças são nelas precipitadas, dando movimento aos processos instituintes. Tomando esse cenário institucional mutante em apreciação, cabe compreender especificamente o objeto deste estudo, a família, evidenciando as transformações mais significativas emergentes nas últimas décadas que ganharam visibilidade social.

\section{Família: Uma Instituição em Movimento}

Nos últimos anos, algumas instituições disciplinares têm sofrido mudanças aceleradas, como é o caso do que se observa na educação, no trabalho e na família, para ficar em apenas alguns exemplos. Analisando especificamente as famílias de hoje, a partir de sua história, constatamos a existência de grupos que estabeleceram vínculos afetivos importantes e que são chamados de vínculos familiares (HINTZ, 2001).

O estudo de Reis (1994) demonstra que nos séculos XVI e XVII, as famílias se dividiam em família aristocrática e família camponesa. Em sua caracterização, o autor demonstra que a primeira vivia da riqueza advinda da exploração da terra. Compartilhavam o mesmo espaço dos castelos a família direta do rei, os parentes, os criados e os dependentes do nobre. O casamento era, antes de tudo, um contrato político e econômico de união de terras para manutenção ou aumento de riquezas. $\mathrm{O}$ trabalho masculino se restringia à administração de terras e às lutas em guerras. Já o trabalho feminino era relativo às atividades sociais no castelo, enquanto criadas e amas de leite se ocupavam das crianças, longe dos pais. Os filhos não necessariamente mantinham um vínculo afetivo direto com seus pais, mas lhes eram ensinados prezar e respeitar a hierarquia familiar.

Naquela mesma época, as famílias camponesas viviam de maneira muito diferente da aristocrática. Apesar de a instituição familiar se fazer presente neste caso, ela não era o círculo social mais importante, tendo em vista que a aldeia (que prezava por uma convivência coletiva) ensinava os regulamentos e as tradições da vida cotidiana. Casamentos também eram arranjados pelas pessoas da aldeia, formando pares considerados "adequados" sob o ponto de vista econômico e social. Assim como ocorria na família aristocrática, as crianças aprendiam a depender de outras pessoas que não seus pais. Apesar de o trabalho feminino estar voltado principalmente para o cuidado das crianças e da casa, o trabalho no campo não deixava tempo suficiente para que essa atenção acontecesse em período integral. Como se pode perceber, não havia muita privacidade nessa organização familiar, uma vez que todos compartilhavam o mesmo ambiente tanto a aristocracia e seus criados no castelo quanto os camponeses que passavam seus dias na aldeia (REIS, 1994).

Com o passar dos séculos, mudanças diversas foram experimentadas na instituição familiar, advindas da economia, da política e da convivência social cotidiana. Ariès (1981, p. 274) ressalta que "a partir do século XVIII, as pessoas começam a se defender contra uma sociedade cujo convívio social constante até então havia sido a fonte da educação, da reputação e da fortuna". Com isso, as famílias 
migraram cada vez mais para o espaço privado, sendo que "em toda parte ele reforçaria a intimidade da vida privada em detrimento das relações de vizinhança, de amizade ou de tradições" (ARIÈS, 1981, p. 274). A emergência social da família nuclear burguesa, que isola um conjunto compactado, formado por pai, mãe e filhos, é compreendida pelo autor como um "esforço do homem para se separar dos outros, para se separar de uma sociedade cuja pressão não pôde ser mais suportada" (ARIÈS, 1981, p. 274). A casa tornou-se, então, uma espécie de refúgio da vida social compartilhada, na qual era possível experimentar um isolamento em relação ao coletivo.

Reis (1994) descreve que no século XIX as constituições familiares mais comuns eram a família proletária e a família burguesa. A primeira se consolidou ainda no final do século XVIII, período inicial da industrialização, em condição quase generalizada de pobreza social e econômica. Naquele período, era comum que os membros da família trabalhassem longas jornadas diárias em fábricas, até mesmo as crianças, e que continuassem a manter laços estreitos de relação com a comunidade. Os filhos eram criados sem muita atenção dos pais, geralmente sob o cuidado de vizinhos, parentes ou simplesmente soltos nas ruas. A família proletária sofreu, ainda no século XIX, pequenas mudanças de melhoria de vida, o que aproximou esse modelo familiar do modelo burguês: as mães de família ficavam em casa com os filhos e com outras mulheres da comunidade, enquanto os homens iam trabalhar.

Mais uma mudança no modo de organização da família proletária aconteceu já no século XX, quando essas famílias se deslocaram para os subúrbios e romperam os laços com a comunidade. Com isso, as mulheres acabaram voltando seus esforços para as tarefas domésticas, enquanto os homens iam trabalhar e os filhos obtinham algum tipo de educação escolar, que se transformou na nova prioridade familiar. Essa última constituição, da família proletária, quase não se diferenciava da família burguesa da mesma época, fato que gerou uma espécie de "aburguesamento" da classe operária no que diz respeito à organização familiar.

Os valores que compunham a família nuclear burguesa já estavam solidificados no século XIX e seguiram fortalecidos no decorrer da primeira metade do século XX. Ao contrário dos outros modelos de família, que atribuíam valor à convivência na comunidade, esta se caracterizou pela separação nítida entre a vida pública e vida privada. O pai saía para o trabalho e lá ele formava sua imagem paterna pública e provedora, enquanto a mãe ficava em casa, preenchendo seu lugar de figura materna, cuidadosa. À medida que a família burguesa se fechava em si mesma (formando uma espécie de dicotomia entre núcleo familiar e sociedade), os filhos ficavam sob total controle dos pais, que eram sua única fonte de afeto. Foucault (2001, p. 311) salienta que "o espaço da família deve ser o espaço de vigilância contínua”, tendo na criança vulnerável seu principal foco. Nessa vigilância, o afeto era operacionalizado em uma espécie de troca: os filhos atendiam as expectativas dos pais de manter o nível social burguês e propagarem a ideologia burguesa e, por isso, recebiam sua proteção.

Mesmo que hoje a constituição nuclear burguesa, formada por pai, mãe e filhos, ainda seja hegemônica, é possível perceber grandes mudanças na sociedade e, com elas, emergiram novos arranjos familiares. Essas mudanças foram precipitadas em diferentes frentes, dentre as quais destacamos o fato de que o casamento deixou de ser um contrato entre o pai da jovem e o seu futuro marido, e deu lugar ao contrato feito entre o homem e a mulher (RAMOS; NASCIMENTO, 2008). Pouco tempo depois, uma parte significativa de mulheres rompeu com os padrões burgueses e deixou de ser a figura materna privada, com função quase exclusivamente ligada à procriação e educação dos filhos, saindo de casa e trabalhando. A mulher também passou a ser uma figura pública e provedora econômica da casa, além de, em alguns casos, ser a chefe da família, papel esse que só era atribuído aos homens (PERUCCHI; 


\section{BEIRÃO, 2007).}

A partir da segunda metade do século XX, houve uma transformação significativa na rede institucional que cooperava para manter fortalecida a família nuclear burguesa. Duas outras instituições passaram a ganhar relevância na educação dos filhos: a escola e a saúde. É nesse sentido que alguns autores (DELEUZE, 1992; DONZELOT, 1986) apontam para uma crise institucional que se consolidou pela abertura do núcleo familiar, outrora fechado, que passou a receber intervenções mais diretas desses dois segmentos (educação e saúde). Donzelot (1986, p. 197) assinala a emergência histórica de uma "crise na família" que tem nos problemas identificados na criança pela escola e tratados pela medicina sua principal marca constitutiva. Os pais também passaram a ser alvo de intervenção, sendo que os casos de separação do casal passaram a ocorrer com maior frequência. Pode-se dizer, então, que essa crise foi um dos marcos que abriu espaço para que, já no final do século XX, outras configurações familiares começassem a ser experimentadas.

Diante desse cenário mutante, torna-se relevante analisar como os grupos familiares, que já não se caracterizam pela triangulação pai-mãe-filhos de laços cosanguíneos, têm acolhido essas mudanças na convivência familiar. É nessa direção que algumas questões ganham importância para este estudo: Como são experimentados os laços afetivos nessas novas organizações familiares? Como são experimentadas as interações sociais com outras configurações familiares? Quais as possibilidades de sustentar essa variação nos modos de constituir uma família? E, por fim, ainda podemos utilizar o termo "família" para compreender essas configurações emergentes?

\section{Século XXI e os Novos Arranjos Familiares}

As mudanças nos conjuntos familiares, que vêm dissolvendo o predomínio social da família nuclear burguesa, tornaram-se foco de diversos estudos acadêmicos (COSTA; DIAS, 2012; FÉRES-
CARNEIRO, 1998; HINTZ, 2001). Estes mostram a relevância e os impactos dessa transformação na atualidade capitalista, em especial no que se refere às transformações sociais e tecnológicas das últimas décadas, à busca pela independência emocional e financeira das mulheres, bem como às novas exigências de competitividade colocadas pelo mercado de trabalho. Outro ponto a ser destacado são as questões referentes às lutas e conquistas por direitos que foram empreendidas, de maneira particular na segunda metade do século XX, pelos movimentos de emancipação das mulheres (CARVALHAES; MANSANO, 2016), dentre os quais enfatizamos os avanços biopolíticos que permitiram o controle sobre a reprodução e os debates sobre a sexualidade feminina.

Como uma das características fundamentais das instituições é a artificialidade, visto contemplar processos de criação e recriação realizados por seus agentes nas relações cotidianas, é inegável a sua constante mutação, já que é o humano quem refaz e, com isso, reinventa as instituições sociais no movimento irredutível entre instituído e instituinte (BAREMBLITT, 2002). A prova de tais mudanças pode ser encontrada nos dados quantitativos obtidos nos censos populacionais realizados pelos órgãos federais de nosso país, bem como nos dados qualitativos que são encontrados em pesquisas diretas com sujeitos que experimentam, de maneira cotidiana, esses novos arranjos. As mudanças também são notadas por aqueles que simplesmente observam e/ou convivem com tais reorganizações familiares.

O IBGE é um dos órgãos de pesquisa que tem sua própria denominação de família. Segundo o instituto, família é compreendida como: "um conjunto de pessoas ligadas por laços de parentesco, dependência doméstica ou normas de convivência, residente na mesma unidade domiciliar ou pessoa que mora só em uma unidade domiciliar" (IBGE, 2012). Assim, as pesquisas realizadas pelo IBGE também colaboram para dar contornos à definição de família na atualidade. Entretanto, ao mesmo 
tempo, tais pesquisas abrem espaços para dúvidas e principalmente incômodos sobre como se dá hoje a constituição de uma família.

Apesar do esforço dos pesquisadores para delimitar a composição de uma estrutura familiar, o resultado do censo apresentado pelo site do governo brasileiro, no ano de 2012, dá indícios da dificuldade de estabelecer uma definição precisa para a família contemporânea. Quando um cidadão responde ao questionário do (IBGE, 2012) e não se identifica com as opções de definição de família apresentadas, pode assinalar a opção "outros". São justamente esses "outros arranjos" que interessaram para esta pesquisa que, nesta seção, buscará analisar três deles: as famílias reconstituídas, as famílias sem filhos e as famílias homoafetivas.

Acompanhando as discussões sobre os novos arranjos da família, percebe-se que a maioria dos debates tem o seu foco nas famílias chamadas por Hintz (2001) como reconstituídas, ou seja, nas famílias formadas a partir de recasamentos tanto hetero quanto homoafetivos. Mesmo não sendo um fato novo, somente no último censo, realizado em 2010, o (IBGE, 2012) passou a contabilizar a incidência das famílias reconstituídas (ou advindas de recasamentos). Segundo o censo, elas somam $16,3 \%$.

Mudanças da organização familiar nuclear burguesa em direção às famílias reconstituídas já não são novidade. Desde que as mulheres começaram a lutar por sua independência econômica, valendo-se do trabalho, durante a revolução industrial e as guerras mundiais, e principalmente depois da liberação sexual, o número de divórcios e de recasamentos começou a crescer e ganhar visibilidade (FÉRES-CARNEIRO, 1998; HINTZ, 2001). Apesar de ser mais comum, a família reconstruída, cujos pais separados optaram por construir um novo casamento, esse é um dos arranjos que, afetivamente, ganha contornos mais complexos. A família reconstituída exige a convivência em uma mesma casa de pessoas que até então não se conheciam. De acordo com Hintz, algumas dificuldades se fazem presentes nesse caso, como, por exemplo, os impasses sobre direitos e deveres de cada membro, dificultando a definição clara dos papéis sociais de cada um em relação a essa nova constituição institucional (HINTZ, 2001).

Para Brito (2007, p. 42), uma das situações mais difíceis de serem vividas na família reconstituída é a elaboração da separação dos casais. Ele mostra, em sua pesquisa, como os filhos experimentaram tal mudança e como se sentem diante da nova constituição. A maioria dos jovens que participou das entrevistas relatou dificuldades em lidar com os novos cônjuges dos pais e, principalmente, com os novos irmãos, dizendo que "não se sentiam em família".

Costa e Dias (2012), por sua vez, investigaram em seu trabalho as reações e afetos experimentados pelos próprios divorciados e recasados. Todos os entrevistados do estudo afirmaram estar infelizes em seu primeiro casamento ou diziam não concordar com o parceiro em questões decisivas, como a disposição para ter ou não novos filhos. Apesar de os pais relatarem que se sentem "realizados" na nova união, Costa e Dias encontraram na fala de seus entrevistados o mesmo discurso dos jovens entrevistados por Brito: os casais recasados relataram que a adaptação de seus filhos com a nova situação conjugal de seus pais foi muito demorada e penosa e, por vezes, os filhos apresentavam argumentos como "você não é meu pai/mãe" para não se relacionarem com o novo cônjuge dos pais.

Féres-Carneiro(1998)indicaqueoindividualismo está intimamente ligado a essas complexas relações pós-divórcio. Os ideais contemporâneos de relações não só conjugais, mas também sociais, enfatizam a prioridade da realização pessoal. O fato de o casal procurar satisfação pessoal e não a ampliação do grupo familiar faz com que a convivência com o cônjuge não seja reconhecida como vantajosa, pois as divergências de desejo e de objetivos pessoais acabam sem espaço. Desse modo, as separações são 
cada vez mais frequentes, assim como demonstram as pesquisas do IBGE, que demarcaram, em 2010, quase o dobro em porcentagem de divórcios quando em comparação ao censo de 2000 (1,7\% em 2000 e $3,1 \%$ em 2010) (IBGE, 2012).

Os dados apresentados acima, referentes à família reconstituída, que também é chamada de mosaico e recasada, não totaliza esta experiência. Apesar de algumas dificuldades iniciais, é possível que uma família formada em virtude de um recasamento possa viver sem grandes traumas (HINTZ, 2001). Um dos grandes problemas, no caso de famílias reconstituídas, é o sentimento de não pertencimento ao novo grupo. Costa e Dias (2012) explicam que os laços sanguíneos de parentesco são evidentes e representam um vínculo perpétuo, enquanto os laços de afeto, definidores dos casamentos reconstituídos, esboçam outro tipo de comprometimento com o novo cônjuge e com sua família anterior. As famílias reconstituídas tentam reproduzir os padrões da família nuclear, mantendo um "equilíbrio da unidade familiar, de forma hierárquica e organizada" (COSTA; DIAS, p. 73). Assim, o fato de manter uma relação de família nuclear é compreendido por eles como algo importante para que haja uma relação mais próxima possível do vínculo sanguíneo. Sobre a definição de família, Hintz (2001) afirma que, não importa sua constituição, uma família será família sempre desde que forem preservadas suas funções de vínculo matrimonial com o objetivo de satisfação sexual e educação dos filhos. Para o autor, a família é um núcleo de proteção, socialização e estabelecimento de vínculos, sejam eles sanguíneos ou não.

Passando para a análise do segundo arranjo familiar, encontramos nos dados do IBGE aquele grupo de indivíduos que não deseja ter filhos. $\mathrm{O}$ tema é incômodo e chama atenção tanto da academia quanto da população em geral. O fenômeno dos casais sem filhos cresce a cada ano: de 2000 a 2010 o índice ampliou em 4,7\% (de 13\% para $17,7 \%$ ) (IBGE, 2012). Esse aumento fez com que reportagens sobre esse tipo de família aparecessem com frequência nas mídias nacional e mundial. O casal Edson Fernandes e Margareth Moura Lacerda, autores de um livro sobre o tema, relatam que um dos motivos pela escolha de não ter filhos foi, além da questão financeira, a possibilidade de dar mais atenção aos seus objetivos: "Nós gostamos de ler e de arte, por exemplo. O casal com filhos, muitas vezes, passa o fim de semana em programas voltados para as crianças e não para eles. Não estou dizendo que são todos, mas isso é frequente. $\mathrm{Eu}$ faço as coisas que gosto sem nenhum impedimento" (NORDI, 2012).

Para fins de realização da pesquisa, o IBGE considerou que casais sem filhos e pessoas morando sozinhas em uma casa também seriam considerados como família, sendo que esses últimos já somam sete milhões de brasileiros. Entretanto, os índices divulgados pelo instituto não fazem distinção entre os casais sem filhos por opção ou por outras razões como, por exemplo, a infertilidade. Pode-se constatar na pesquisa de Rios e Gomes (2009, p. 224) que um dos aspectos centrais tomados em consideração na opção por ter ou não filhos está precisamente no "poder escolher" que incide sobre os mais diversos aspectos da existência, "independentemente daquilo que se escolhe". Tal possibilidade de escolha só pode ser considerada quando o modelo familiar burguês (pai, mãe e filhos) já está em processo de questionamento e mutação.

De todo modo, Hintz (2001) assinala que, nos dois casos (pessoas que moram sozinhas e casais sem filhos), os indivíduos cada vez mais avaliam suas necessidades, priorizando elementos que os satisfaçam como, por exemplo, a ascensão profissional e socioeconômica. Adiferença se dá pelo fato de que os indivíduos que moram sozinhos não necessariamente precisam manter relações afetivas mais frequentes em um espaço compartilhado, havendo grande valorização da individualidade e do espaço pessoal. O censo realizado pelo (IBGE, 2012) comprova que existe um aumento de 
contextos familiares com essas características, uma vez que os casais sem filhos, por exemplo, somam $20,7 \%$ das famílias nucleares.

Chegamos, então, ao terceiro arranjo familiar a ser analisado: os casais homoafetivos. Como já dito, o censo de 2010 (IBGE, 2012), foi o primeiro a considerar a união de parceiros do mesmo sexo, mas, nesse caso, não os definiu como família. Segundo os dados, $99,6 \%$ dos casais homoafetivos viviam em união consensual, tipo de união que sofreu um aumento significativo tanto para homossexuais quanto para heterossexuais. Uziel (2006) descreveu a evolução dos movimentos homossexuais no Brasil desde a década de 1970 e apontou o crescimento desse índice na atualidade. A partir dessa mudança, foi possível legalizar, em 2011, a união estável e a união civil de casais homossexuais. Esta última, segundo o Supremo Tribunal Federal (STF), foi caracterizada como família (ARAÚJO, 2013). Com isso, foi possível que casais homoafetivos pudessem se consolidar como um novo arranjo familiar que, por sua vez, se desdobra nas seguintes configurações: uma família de dois pais ou de duas mães, com filhos adotados ou de sangue (ARAÚJO, 2013; HINTZ, 2001).

Zauli (2011) entrevistou, em sua pesquisa, famílias homoafetivas de mulheres e seus filhos. $\mathrm{Na}$ maioria dos casos estudados, o filho era tutelado por apenas uma das mães, havendo poucas situações de guarda ou adoção compartilhada. Em alguns casos, as mães já tinham filhos de relações heterossexuais anteriores. Isso mostra o quão complexa é essa configuração familiar, uma vez que pode envolver desde o recasamento, passando pela adoção de crianças em conjunto ou separadamente. Zauli(2011) ainda mostra que existe nesse arranjo familiar uma dificuldade semelhante àquela encontrada entre nas famílias reconstituídas que envolvia a denominação dos seus membros e a definição de papéis sociais.

Existem diversos obstáculos para que novos arranjos familiares sejam acolhidos e sustentados na denominação e caracterização da instituição família. Por não se "encaixar" no modelo nuclear burguês ou seguir a norma heterossexual, esse novo arranjo familiar enfrenta dificuldades próprias, pois "há pressões e circunstâncias, mitos e realidades específicos que afetam estes casais" (HINTZ, 2001, p. 10).

As estatísticas apresentadas pelo (IBGE, 2012) são importantes para evidenciar o número aproximado de brasileiros que vivem em diferentes grupos familiares, sendo evidentes as mudanças em curso. Tomando em consideração tais dados, é possível recorrer ao estudo de Singly (2007) no qual o autor demonstra a crescente intervenção do Estado nas instituições, em especial na instituição família. Dentre as mudanças destacadas pelo autor está a concepção, socialmente compartilhada, de que a família seria um espaço privado protegido, mas que, ao mesmo tempo, enfrenta as intervenções diretas do Estado que se coloca como responsável por mediar e regulamentar as relações entre seus membros (pais e filhos) bem como exercer o direito de punição sobre os pais que não assumem ou deixam a desejar na sua função tutelar.

Corroborando com a discussão realizada pelo autor, pudemos acompanhar em nosso país a elaboração e aprovação do Projeto de Lei, $n^{\circ}$. 6.583, de autoria do deputado federal Anderson Ferreira, sobre o chamado "Estatuto da Família". Essa proposta de lei foi apresentada no final de 2013 e aprovada em 2015. A partir dela, foi disponibilizada, no site da Câmara dos Deputados, uma enquete pública que perguntava ao cidadão se a seguinte definição de família é a mais correta para a sociedade brasileira: "Art. $2^{\circ}$ Para os fins desta Lei, define-se entidade familiar como o núcleo social formado a partir da união entre um homem e uma mulher, por meio de casamento ou união estável, ou ainda por comunidade formada por qualquer dos pais e seus descendentes" (BRASIL, 2013).

A elaboração desse polêmico projeto de lei sobre famílias buscou levar em consideração a maneira como a população compreende a noção de família. 
O resultado da enquete mostrou que até julho de 2014, a maior parte dos votos foi concordante com a definição de família como sendo um arranjo nos modos da família nuclear, composta por pai, mãe e filhos $(60,13 \%$ ou 712.555 votos). Na página em que se encontra a enquete (BRASIL, 2014), estão disponibilizados espaços para fazer comentários, sendo que a maioria deles coloca-se a favor do modo dominante de formação familiar e fundamenta sua opinião na religião, na tradição ou mesmo na biologia.

Tais comentários colaboram para compreender como as normas familiares burguesas instituídas encontram-se fortalecidas e naturalizadas. Como uma instituição cristalizada a mais de 200 anos, a família burguesa tende a ser protegida por seus agentes, uma vez que essa constituição familiar continua a desempenhar funções de propagadora da ideologia burguesa e de formadora da divisão entre núcleo familiar e sociedade. Acontece que essa constituição de família, assim como outras instituições centenárias, ganham contornos de naturalidade, sendo compreendidas como lógicas e eternas. Entretanto, tal como visto com Baremblitt (2002), esta instituição não passa de mais uma criação do homem. Segundo o autor, a vida social é entendida como um processo em permanente transformação e ruptura. Isso ocorre, como já dito, tomando em consideração um enfrentamento constante entre as dimensões de instituído e instituinte que atravessam toda instituição social. Quando o movimento de debate, disputa e enfrentamento não é considerado, a dimensão instituída ganha a cena e as avaliações podem levar o debate majoritariamente para o campo moral.

Mesmo que a quantidade de votos na enquete seja somente de cerca de um milhão de participantes (1.185.048 votos até o dia 05/07/14), é possível dizer que essa participação é relevante para o contexto desta investigação, uma vez que os comentários feitos na enquete em questão mostram que parte significativa das pessoas não identifica como sendo uma família os grupos formados por recasamentos, um só progenitor, casais sem filhos e casais homoafetivos com filhos, fato que merece uma apreciação.

\section{Considerações Finais}

As caracterizações da instituição familiar apresentadas neste trabalho são somente uma fração dos novos tipos de família ou de grupos familiares que vêm se configurando e/ou ganhando visibilidade nos últimos anos. Ao mesmo tempo, eles podem ser considerados índices das constantes mudanças que as instituições normativas sofrem; mudanças estas que colocam em andamento a transformação da vida em sociedade. É possível dizer que os agentes desses novos arranjos familiares colocam em curso uma dimensão instituinte da família, agregando e experimentando novos valores, sensibilidades e relações. A formação de uma família, nesses casos, não acolhe a tarefa de "encaixar" diferentes pessoas nos papéis já conhecidos advindos da configuração nuclear burguesa, mas empenha-se em criar maneiras singulares de viver em um grupo que toma em apreciação os afetos e as experimentações emergentes na vinculação com o meio social.

A pesquisa também demonstrou que, para um contingente significativo da população, a questão da realização pessoal coloca-se acima da necessidade de reproduzir um tipo de grupo social que vive conforme os códigos mais antigos, como a família burguesa. Assim, em função da busca pela satisfação pessoal, os sujeitos, por vezes, acabam priorizando a opção tardia por ter filhos ou mesmo a escolha por não tê-los.

Outro tema abordado foi o fato de haver projetos de lei, como o "Estatuto da Família" que, de certo modo, busca intervir na dinâmica mutante das instituições, com vistas à sua conservação. Em alguma medida, esse tipo de iniciativa pretende levar para o plano legal os múltiplos impasses atualizados nas relações afetivas. No projeto de lei analisado, entretanto, está previsto somente um tipo de família: aquela formada por um casal 
heterossexual e seus filhos. É notável o quanto esse tipo de projeto reforça os padrões da família nuclear burguesa e tende a tomá-la como modelo universal, em detrimento à mutação social que, como dito, é vital e se faz presente em toda instituição. Desconsiderar seu movimento é inaceitável, uma vez que isso abriria espaço para formas de exclusão e preconceito no tocante ao que advém como novo no meio social.

Diante dessa tentativa de legislar sobre as relações afetivas, foi importante voltar o olhar para a família como instituição, que é marcada por mudanças e rupturas. Assim, consideramos que esse ensejo de regulamentação jurídica da família é, no mínimo, preocupante e nos leva a questionar: É possível acolher a ideia de uma instância legal que normatize os afetos, os arranjos familiares, suas diferentes composições e modos de vida? Isso não nos levaria a uma insustentabilidade da vida afetiva, que passa a ser esquadrinhada e prescrita pela lei? Trata-se de uma problematização que está longe de ser superada, tendo em vista os múltiplos aspectos (econômicos, sociais, políticos e relacionais) que nela estão implicados e que se desdobram em novos questionamentos e rupturas institucionais.

Nesse sentido, acolher e sustentar o movimento de transformação nas experimentações afetivas presentes nas instituições mostra-se algo ao mesmo tempo difícil e necessário. A sustentabilidade, aqui, refere-se à possibilidade de criar espaços de expressão e suporte às mudanças que vêm tomando conta do âmbito familiar nas diferentes classes sociais e econômicas de nosso país. Quando o Estado tenta legislar sobre a instituição família e seus desdobramentos na esfera da vida privada, suas intervenções podem tomar contornos insustentáveis e autoritários, disseminando práticas de coerção que priorizam a difusão modelos rígidos a serem simplesmente reproduzidos.

Assim, é indispensável atentar para os afetos que emergem dessas composições múltiplas e para as formas como, tanto os integrantes das novas famílias quando a sociedade em geral, sustentarão as novas maneiras de experimentar a família. Ao mesmo tempo, cabe continuar acompanhando como a família tradicional burguesa está abrindo (ou não) espaços para dialogar e conviver com os diferentes traços que a redesenham, nas fronteiras da experimentação. A distância da configuração burguesa já é notável, o que nos leva a questionar se ainda é possível manter a mesma denominação "família" para os novos arranjos, em especial para aqueles que não envolvem a presença de filhos.

Os primeiros passos nessa direção já estão sendo dados e são perceptíveis nas estatísticas. Ao mesmo tempo, é perceptível a dificuldade social para acolher e sustentar o movimento de transformação, tendo em vista as tentativas insistentes de intervenção para conservar os valores mais tradicionais da vida institucional. O que vemos, portanto, é que a instituição familiar move-se independentemente dos valores conservadores, gerando uma série de debates, incômodos e reações sociais em relação aos seus novos contornos.

\section{Referências}

ARAÚJO, G. F. O papel estratégico da mídia na formação da opinião pública: o caso da aprovação da "união civil homoafetiva" no Brasil. 2013. Disponível em: $\quad<$ http://www.compolitica.org/home/wp-content/ uploads $/ 2013 / 05 /$ GT-06-cultura-pol $\%$ C3\%adticacomportamento-e-opini\%C3\%A3o-p\%C3\%bablicaGilvan-F.-de-Araujo.pdf $>$. Acesso em: 3 jun. 2016.

ARIÈS, P. A História social da cirança e da família. Rio de Janeiro: LTC, 1981.

BAREMBLITT, G. F. Compêndio de análise institucional e outras correntes: teoria e prática. 2. ed. Rio de Janeiro: Rosa dos Tempos, 1994.

Compêndio de análise institucional e outras correntes: teoria e prática. Belo Horizonte: Instituto Feliz Guattari, 2002.

BRASIL. Câmara dos Deputados. Enquetes realizadas. 2014. Disponível em: <http://www2.camara.leg.br/ agencia-app/votarEnquete/enquete/101CE64E-8EC3436C-BB4A-457EBC94DF4E>. Acesso em: 3 jun. 2016. 
Projeto de Lei 6583, de 2013. Dispõe sobre o Estatuto da Família e dá outras providências. 2013. Disponível em: <http://www.camara.gov.br/ proposicoesWeb/prop_mostrarintegra;jsessionid=5FC0 6D0A1AB6937473330A251871F182.proposicoesWeb1 ?codteor $=1159761 \&$ filename $=\mathrm{PL}+6583 / 2013>$. Acesso em: 3 jun. 2016.

BRITO, L. M. T. Família pós-divórcio: a visão dos filhos. Psicologia: Ciência e Profissão, v. 27, n. 1, p. 32-45, 2007.

CARVALHAES, F. F.; MANSANO, S. R. V. R. Mulheres e lutas políticas: conquistas e limites vividos na segunda metade do século XX. INTERthesis, Florianópolis, v. 13, n. 2, p. 141-164 maio/ago. 2016.

COSTA, J. M.; DIAS, C. M. S. B. Famílias recasadas: mudanças, desafios e potencialidades. Psicologia: Teoria e Prática, São Paulo, v. 14, n. 3, p. 72-87, 2012.

DELEUZE, G. Conversações. Rio de Janeiro: Ed. 34, 1992.

DONZELOT, J. A polícia das famílias. Rio de Janeiro: Graal, 1986.

FÉRES-CARNEIRO, T. Casamento contemporâneo: o difícil convívio da individualidade com a conjugalidade. Psicologia: reflexão e Crítica, v. 11, n. 2, p. 379-394, 1998.

FOUCAULT, M. As anormais: curso do Collège de France (1974-1975). São Paulo: M. Fontes, 2001.

Vigiar e punir: nascimento da prisão. Petrópolis $\overline{\text { : Vozes, }} 1987$.

HINTZ, H. C. Novos tempos, novas famílias? Da modernidade a pós modernidade. Pensando Famílias, Porto Alegre, v. 3, n. 3, p. 8-19, 2001.

HOUAISS, A.; VILAR, M. Dicionário Houaiss da Língua Portuguesa. Rio de Janeiro: Objetiva, 2009.

IBGE. Censo demográfico 2010: resultados gerais da amostra. Rio de Janeiro, 2012.
LOURAU, R. A análise institucional. Petrópolis: Vozes, 1995.

MANSANO, S. R. V. Espaço urbano, natureza e relação sociais: por uma sustentabilidade afetiva. Psicologia: Teoria e Prática, São Paulo, v. 17, n. 3, p. 49-59, jan./ abr. 2016.

NORDI, D. A vida sem filhos é melhor? $I G$, São Paulo, 11 jun. 2012. Delas. Disponível em: $<$ http://delas.ig.com. br/filhos/2012-06-11/a-vida-sem-filhos-e-melhor.html>. Acesso em: 3 jun. 2016.

PERUCCI, J.; BEIRÃO, A. M. Novos arranjos familiares: paternidade, parentalidade e relações de gênero sob o olhar de mulheres chefes de família. Psicologia Clínica, Rio de Janeiro, v. 2, p. 57-69, 2007.

RAMOS, D. M. D.; NASCIMENTO, V. G. D. A família como instituição moderna. Fractal: Revista de Psicologia, Rio de Janeiro, v. 20, n. 2, p. 461-472, jul./ dec. 2008.

REIS, J. R. T. Família, emoção e ideologia. In: LANE, S. T. M.; CODO, W. (Org.). Psicologia social: o homem em movimento. São Paulo: Brasiliense, 1994.

RIOS, M. G.; GOMES, I. C. Casamento contemporâneo: revisão de literatura acerca da opção por não ter filhos. Estudos de Psicologia, Campinas, v. 26, n. 2, p. 215-225, abr./jun. 2009.

SINGLY, F. Sociologia da família contemporânea. Rio de Janeiro: Ed. da FGV, 2007.

UZIEL, A. P. et al. Parentalidade e conjugalidade: aparições no movimento homossexual. Horizontes Antropológicos, Porto Alegre, ano 12, n. 26, p. 203-227, ju./dez. 2006.

ZAULI, A. Famílias homoafetivas femininas no Brasil e no Canadá: um estudo transcultural sobre novas vivências nas relações de gênero e nos laços de parentesco. Tese (Doutorado em Psicologia Social, do Trabalho e das Organizações) - Universidade de Brasília, Brasília, 2011. 
